\title{
Analisis Kepuasan Pelanggan Pada Cafe Kota Cinema Mall, Bekasi
}

\author{
Kartika Yuliantari ${ }^{1}$, Kus Daru Widayati ${ }^{2}$ \\ ${ }^{1,2}$ Universitas Bina Sarana Informatika \\ ${ }^{1}$ e-mail: kartika.kkj@bsi.ac.id \\ ${ }^{2}$ e-mail: kus.kdr@bsi.ac.id

\begin{tabular}{ccc}
\hline Diterima & Direvisi & Disetujui \\
$02-09-2019$ & $04-09-2019$ & $17-09-2019$
\end{tabular}

\begin{abstract}
Abstrak - Perputaran dunia ekonomi secara global sangat cepat. Hal ini erat kaitannya dengan dunia bisnis yang semakin berkembang. Agar tetap survive maka banyak cara pengusaha lakukan agar usahanya tidak kalah bersaing dengan usaha lainnya. Pelayanan kepada pelanggan merupakan hal yang penting dan harus diutamakan karena pelanggan menginginkan pelayanan yang dapat memuaskannya. Oleh karena itu, perusahaan harus berusaha mendapatkan informasi tentang hal yang dibutuhkan pelanggan sehingga perusahaan dapat memuaskan pelanggan. Cafe di Kota Cinema Mall, Bekasi merupakan perusahaan yang bergerak di bidang jasa, permasalahan yang akan dibahas dan diteliti adalah menganalisis tingkat kepuasan pelanggan di Café dalam memilih produk pada saat menonton film di Kota Cinema Mall, Bekasi. Dengan mengetahui tingkat kepuasan pelanggan maka bertujuan untuk memenuhi keinginan pelanggan agar pelanggan dapat terpuaskan. Pengambilan sampel menggunakan metode non probability sampling, jenisnya adalah Accidental sampling. Jumlah sampel responden yang diambil oleh peneliti sebanyak 50 orang konsumen yang berkunjung di Cafe Kota Cinema Mall, Bekasi untuk menonton dan membeli kebab secara acak pada periode Juli 2019. Metode pengumpulan data adalah data primer melalui wawancara terstruktur. Metode analisis data secara kualitatif deskriptif dengan menggunakan Customer Satisfaction Index (CSI), yaitu dengan melakukan pembobotan terhadap tingkat kepuasan dari atribut produk fisik dan jasa Cafe di Kota Cinema Mall menurut konsumen. Hasil dari penelitian ini Analisis kepuasan pelanggan berdasarkan bauran pemasaran yang diteliti penulis berdasarkan produk, harga, saluran distribusi, promosi, bukti fisik, proses dan orang yaitu pelanggan secara keseluruhan menyatakan sangat puas terhadap kebab yang disajikan di Cafe di Kota Cinema Mall, Bekasi.
\end{abstract}

Kata Kunci: Analisis, Kepuasan, Pelanggan

Abstract - The global economic cycle is very fast. This is closely related to the growing business world. In order to survive, there are many ways entrepreneurs do it so that their business does not compete with other businesses. Service to customers is important and must be prioritized because customers want services that can satisfy it. Therefore, the company must try to get information about what is needed by the customer so that the company can satisfy the customer. Cafe in the City Cinema Mall, Bekasi is a company engaged in services, the problem to be discussed and researched is analyzing the level of customer satisfaction at the Café in choosing products when watching movies in the City Cinema Mall, Bekasi. By knowing the level of customer satisfaction it aims to meet customer desires so that customers can be satisfied. Sampling using non-probability sampling method, the type is accidental sampling. The number of respondents taken by researchers as many as 50 consumers who visited the Cinema City Cafe Mall, Bekasi to watch and buy kebabs randomly in the period July 2019. Data collection methods are primary data through structured interviews. The method of analyzing data is qualitatively descriptive using the Customer Satisfaction Index (CSI), namely by weighting the satisfaction levels of physical product attributes and Cafe services in the Cinema Mall City according to consumers. The results of this study Analysis of customer satisfaction based on the marketing mix investigated by the author based on products, prices, distribution channels, promotions, physical evidence, processes and people, that is the customer as a whole expressed very satisfied with the kebabs served at the Cafe in the City Cinema Mall, Bekasi.

Keywords: Analysis, Satisfaction, Customers

\section{PENDAHULUAN}

Pertumbuhan usaha yang semakin pesat saat ini, ternyata berhasil menciptakan persaingan pasar yang semakin ketat. Keadaan ini memaksa para pengusaha untuk menggunakan berbagai cara dalam menggunakan strategi pemasaran mereka. Banyak cara yang mereka lakukan agar usahanya tidak kalah bersaing dengan peluang usaha lainnya, sehingga masih bisa bertahan bahkan berkembang ditengah persaingan pasar yang semakin ramai.Persaingan dapat terjadi dalam hal harga, 
kualitas, maupun promosi yang dilakukan setiap perusahaan. Apabila perusahaan ingin tetap bertahan dalam persaingan di dunia bisnis maka mereka harus dapat menjadikan pelanggan menjadi pelanggan tetap dengan cara memberikan kepuasan kepada pelanggan. Pelanggan akan terpuaskan apabila kebutuhan yang diinginkan dapat terpenuhi yaitu dengan memberikan produk yang mutunya terjamin dengan baik, memberikan jasa pelayanan yang baik sehingga pelanggan merasa sangat nyaman dalam menggunakan jasa pelayanan tersebut, serta tersedianya fasilitas yang bagus untuk mendukung jasa pelayanan yang perusahaan berikan pada pelanggan. Oleh karena itu, perusahaan harus berusaha mendapatkan informasi tentang hal yang dibutuhkan pelanggan sehingga perusahaan dapat memuaskan pelanggan.

Cafe di Kota Cinema Mall, Bekasi merupakan perusahaan yang bergerak di bidang jasa, pelayanan kepada pelanggan merupakan hal yang penting dan harus diutamakan karena pelanggan menginginkan pelayanan yang dapat memuaskannya. Semakin baik perusahaan memberikan pelayanan terhadap pelanggan, maka pelanggan akan lebih memilih menggunakan jasa pelayanan di perusahaan tersebut dari pada perusahaan pesaingnya.

Berdasarkan latar belakang tersebut, maka permasalahan yang akan dibahas dan diteliti adalah analisis analisis kepuasan pelanggan berdasarkan bauran pemasaran yang diteliti penulis berdasarkan produk, harga, saluran distribusi, promosi, bukti fisik, proses dan orang yaitu pelanggan menyatakan puas terhadap popcorn yang disajikan di Café Cinema XXI Pondok Gede, Bekasi.

\section{Pengertian Kepuasan Pelanggan}

Menurut Kotler dalam (Atmaja, 2018) mengemukakan bahwa "kepuasan pelanggan adalah perasaan senang atau kecewa seorang yang muncul setelah membandingkan antara kinerja (hasil) produk yang diperkirakan terhadap kinerja yang diharapkan".

Sedangkan menurut Rangkuti dalam (Sazly, 2018) mengemukakan bahwa"kepuasan pelanggan adalah sejauh mana harapan pelanggan terhadap produk atau jasa yang diberikan dan telah sesuai dengan aktual produk atau jasa yang ia rasakan”.

\section{Faktor-Faktor Yang Mempengaruhi Kepuasan Pelanggan}

Dalam menentukan kepuasan konsumen ada lima faktor yang harus diperhatikan oleh perusahaan menurut Lupoyoadi dalam (Atmaja, 2018) antara lain:

a. Kualitas produk, pelanggan akan berasa puas bila hasil mereka menunjukan bahwa produk yang mereka gunakan berkualitas.

b. Kualitas pelayanan atau jasa, yaitu pelanggan akan merasa puas bila mereka mendapatkan pelayanan yang baik atau sesuai dengan yang diharapkan.

c. Emosi, yaitu pelanggan akan merasa bangga dan mendapatkan keyakinan bahwa orang lain akan kagum terhadap dia bila menggunakan produk dengan merek tertentu yang cenderung memiliki tingkat kepuasan yang lebih tinggi. Kepuasan yang diperoleh bukan karena kualitas dari produk tetapi sosial atau self esteem yang membuat pelanggan merasa puas terhadap merek tertentu.

d. Harga, yaitu produk yang mempunyai kualitas yang sama tetapi tetapkan harga yang relatif murah akan memberikan nilai yang lebih tinggi kepada pelanggan.

e. Biaya, yaitu pelanggan yang tidak perlu mengeluarkan biaya tambahan atau tidak perlu membuang waktu untuk mendapatkan suatu produk atau jasa cenderung puas terhadap produk atau jasa tersebut.

\section{Bauran Pemasaran}

Menurut Sunyoto dalam (Fachriza \& Moeliono, 2017) mengemukakan bahwa "bauran pemasaran adalah kombinasi dari empat elemen pokok yang terdapat dalam program pemasaran perusahaan meliputi product, price, place, promotion".

Adapun menurut Buchari Alma dalam (Ningratri, 2017) mengemukakan bahwa "marketing mix merupakan strategi mencampur kegiatankegiatan maksimal, agar dicari kombinasi maksimal sehingga mendatangkan hasil yang paling memuaskan".

Menurut Tjiptono dalam (Pradiatiningtyas, 2015) mengemukakan bahwa bauran pemasaran merupakan seperangkat alat yang dapat digunakan pemasar untuk membentuk karakteristik jasa yang ditawarkan kepada pelanggan. Sedangkan bauran pemasaran jasa dikelompokkan menjadi komponen "7 P", yakni:

a. Produk (Products)

Merupakan bentuk penawaran organisasi jasa yang ditujukan untuk mencapai tujuan melalui pemuasan kebutuhan dan keinginan pelanggan. Produk disini bisa berupa apa saja (baik yang berwujud fisik maupun tidak) yang dapat ditawarkan kepada pelanggan potensial untuk memenuhi kebutuhan dan keinginan tertentu. Produk merupakan semua yang ditawarkan ke pasar untuk diperhatikan, diperoleh dan digunakan atau dikonsumsi untuk dapat memenuhi kebutuhan dan keinginan yang berupa fisik, jasa, orang, organisasi dan ide. Hal ini sangat berimplikasi pada pencapaian kepuasan konumen (guestsatisfaction).

b. Harga (Price)

Bauran harga berkenaan dengan kebijakan strategis dan praktaktis, harga meggambarkan besarnya rupiah yang harus dikeluarkan seorang konsumen untuk memperoleh satu buah produk dan hendaknya harga akan dapat terjangkau oleh konsumen sehingga yang harus diperhatikan adalah bagaimana harga dapat menjadi daya tarik bagi konsumen karena konsumen sudah mengorbankan sejumlah uang untuk mendapatkan kepuasan, apabila konsumen tidak 
mendapatkan apa yang diinginkan maka yang terjadi adalah konsumen menghentikan pembelian atas suatu produk.

c. Saluran Distribusi (Place)

Merupakan keputusan distribusi menyangkut kemudahan akses terhadap jasa bagi para konsumen yang memungkinkan mereka dapat dengan mudah sampai pada tujuan.

d. Promosi (Promotion)

Bauran promosi adalah ramuan khusus dari iklan pribadi, promosi penjualan dan hubungan masyarakat yang dipergunakan perusahaan untuk mencapai tujuan iklan dan pemasarannya. Bauran promosi yang dipilih oleh suatu perusahaan bagi suatu produk atau jasa tergantung pada beberapa faktor: sifat produk, tahapan dalam daur hidup produk, karakteristik target pasar, jenis keputusan pembelian, tersedianya dana untuk promosi dan menggunakan baik strategi mendorong (push) maupun menarik ( $p u l l$ ).

e. Bukti Fisik (Physical Evidence)

Karakteristik intangible pada jasamenyebabkan pelanggan potensial tidak bisa menilai suatu jasa sebelum mengkonsumsinya. Ini meyebabkan risiko yang dipersepsikan konsumen dalam keputusan pembelian semakin besar. Oleh sebab itu, salah satu unsur penting dalam bauran pemasaran adalah mengurangi tingkat risiko tersebut dengan jalan menawarkan bukti fisik dari karakteristik jasa. Bukti fisik dari sebuah suatu usaha jasa dapat meliputi lokasi atau tempat itu sendiri, papan nama penunjuk arah atau penanda lokasi, bangunan dan lain sebagainya.

f. Proses (Process)

Proses produksi atau operasi merupakan faktor penting bagi konsumen high contact service yang seringkali berperan sebagai co-producer jasa bersangkutan. Dalam bisnis jasa, manajemen pemasaran dan manajemen operasiterkait erat dan sulit dibedakan dengan tegas.Proses dalam konteks usaha jasa adalah bagaimana pelayanan atas jasa dirasakan dan sampai kepada pelanggan.

g. Orang (People)

Bagi sebagian besar jasa, orang merupakan unsur vital dalam bauran pemasaran. Dalam industri jasa, setiap orang merupakan "parttime marketer" yang tindakan dan perilakunya memiliki dampak langsung terhadap outputyang diterima pelanggan. Orang-orang yang berada dalam proses pengantaran jasa sampai dapat dinikmati oleh konsumen merupakan salah satu elemen bauran pemasaran.

\section{Penelitian Terdahulu}

Penelitian terdahulu yang pernah membahas tentang analisis kepuasan pelanggan adalah Analisis Kepuasan Konsumen Terhadap Kedai Kopi Ulee Kareng di Kota Medan oleh T. Risha Sefilla Chairawani, Iskandarini, dan Emalisa dari Journal on Social Economy of Agriculture and Agribusines. (Chairawani, Iskandarin, \& Emalisa, 2018)

\section{METODOLOGI PENELITIAN}

Pengambilan sampel atau disebut juga responden dilakukan dengan menggunakan metode non probability sampling, jenisnya adalah Accidental sampling yang dilakukan dengan cara memperoleh data dari sekumpulan populasi, yang cara memperoleh data untuk sampel tersebut dengan cara insidental atau secara kebetulan saja dengan tidak menggunakan perencanaan tertentu. Responden diambil adalah konsumen yang berkunjung untu menonton dan membeli kebab di Cafe di Kota Cinema Mall, Bekasi. (Mardalis., 2004). Menurut (Kotler \& Gary Armstrong, 2009), ukuran sampel minuman yang dapat diterima bisa dilihat berdasarkan pada desain atau metode penelitian yang digunakan. Jika desain penelitiannya deskriptif - korelasional, maka sampel minimum adalah 30 responden. Jumlah responden yang diambil oleh peneliti sebanyak 50 orang diambil dari konsumen yang berkunjung di Cafe Kota Cinema Mall, Bekasi untuk menonton dan membeli kebab secara acak pada periode Juli 2019 karena sudah memenuhi syarat sampel data agar tersebar secara normal dalam statistik.

Metode pengumpulan data pada penelitian ini adalah data primer yang diperoleh dengan melakukan tanya jawab kepada responden para pelanggan yang datang menonton di Cafe di Kota Cinema Mall, Bekasi. Jenis pertanyaan dalam kuesioner tersebut adalah pertanyaan berstruktur yaitu dengan teknik pengumpulan data dari pertanyaan-pertanyaaan tertulis yang alternatif jawabannya pun telah disiapkan.

Metode analisis data tingkat kepuasan konsumen pada Cafe di Kota Cinema Mall di daerah penelitian secara kualitatif deskriptif dengan menggunakan Customer Satisfaction Index (CSI), yaitu dengan melakukan pembobotan terhadap tingkat kepuasan dari atribut produk fisik dan jasa Cafe di Kota Cinema Mall menurut konsumen, sehingga akan diperoleh indeks kepuasan konsumen keseluruhan. Rs $=(m-n): b$

Dimana:

Rs = Rentang Skala

$\mathrm{m}$ = Jumlah Skor Tertinggi (Nilai Skor Tertinggi (5) $\mathrm{x}$ Jumlah Indikator dari Komponen Bauran Pemasaran)

$\mathrm{n}$ = Jumlah Skor Terendah (Nilai Skor Terendah (1) $\mathrm{x}$ Jumlah Indikator dari Komponen Bauran Pemasaran)

$\mathrm{b}=$ Jumlah Kelas (dalam penelitian ini digunakan lima kategori kelas sesuai dengan skala Likert)

\section{HASIL DAN PEMBAHASAN}

Sebelum membahas tentang kepuasan pelanggan, terlebih dahul penulis akan mengindetifikasi karakteristik pelanggan yang membeli kebab di Cafe Kota Cinema Mall, Bekasi dengan menggunakan wawancara terstruktur, sebagai berikut: 
Tabel 1. Karakteristik Pelanggan di Cafe Kota Cinema Mall, Bekasi (Periode Juli 2019)

\begin{tabular}{|c|c|c|c|}
\hline \multicolumn{4}{|c|}{ Karakteristik Pelanggan Berdasarkan Jenis Kelamin } \\
\hline No & Jenis Kelamin & Jumlah & Persentase \\
\hline 1 & Laki-Laki & 32 & $64 \%$ \\
\hline \multirow[t]{2}{*}{2} & Perempuan & 18 & $36 \%$ \\
\hline & TOTAL & 50 & $100 \%$ \\
\hline \multicolumn{4}{|c|}{ Karakteristik Pelanggan Berdasarkan Umur } \\
\hline No & Umur & Jumlah & Persentase \\
\hline 1 & 15-20 tahun & 10 & $20 \%$ \\
\hline 2 & $21-25$ tahun & 25 & $50 \%$ \\
\hline 3 & $26-30$ tahun & 8 & $16 \%$ \\
\hline \multirow[t]{2}{*}{4} & $31-40$ tahun & 7 & $14 \%$ \\
\hline & TOTAL & 50 & $100 \%$ \\
\hline \multicolumn{4}{|c|}{ Karateristik Pelanggan Berdasarkan Pekerjaan } \\
\hline No & Pekerjaan & Jumlah & Persentase \\
\hline 1 & Karyawan Swasta & 19 & $38 \%$ \\
\hline 2 & Wiraswasta & 4 & $8 \%$ \\
\hline 3 & PNS & 2 & $4 \%$ \\
\hline 4 & Mahasiswa/Pelajar & 22 & $44 \%$ \\
\hline \multirow[t]{2}{*}{5} & Ibu Rumah Tangga & 3 & $6 \%$ \\
\hline & TOTAL & 50 & $100 \%$ \\
\hline \multicolumn{4}{|c|}{ Karakteristik Pelanggan Berdasarkan Penghasilan } \\
\hline No & Penghasilan & Jumlah & Persentase \\
\hline 1 & Belum Berpenghasilan & 18 & $36 \%$ \\
\hline 2 & Rp 2.000.000,00 & 2 & $4 \%$ \\
\hline 3 & Rp 4.000.000,00 & 9 & $18 \%$ \\
\hline 4 & $\mathrm{Rp} 6.000 .000,00$ & 14 & $28 \%$ \\
\hline \multirow[t]{2}{*}{5} & $\mathrm{Rp} \quad 8.000 .000,00$ & 7 & $14 \%$ \\
\hline & TOTAL & 50 & $100 \%$ \\
\hline
\end{tabular}

Sumber: Data diolah Ms Excel 2010 (2019)

Karakteristik Pelanggan di Cafe Kota Cinema Mall, Bekasi yang lebih sering berkunjung adalah pelanggan yang berjenis kelamin laki-laki, pelanggan yang berumur 21-25 tahun, pelanggan yang berprofesi mahasiswa/pelajar dan bekerja sebagai karyawan swasata, serta pelanggan berpenghasilan Rp $6.000 .000,00$.

Peneliti menganalisis tingkat kepuasan pelanggan terhadap kebab pada Cafe Kota Cinema Mall, Bekasi dengan menggunakan wawancara terstruktur berdasarkan bauran pemasaran sebagai acuan untuk membuat pernyataan. berikut merupakan hasil jawaban dari wawancara terstruktur:

\section{A. Tingkat Kepuasan Berdasarkan Produk}

Berdasarkan hasil observasi dan wawancara terstruktur, penulis mendapatkan hasil jawaban pelanggan pada tingkat kepuasan berdasarkan produk, sebagai berikut:

\section{Cita Rasa Kebab di Cafe Kota Cinema Mall, Bekasi}

Berdasarkan observasi penulis, pada Café Kota Cinema Mall, Bekasi, menyediakan kebab dengan berbagai pilihan rasa yaitu original, sweet glass, dan caramel. Berikut hasil wawancara terstruktur kepada pelanggan tentang cita rasa kebab yang best seller yaitu original kebab:
Tabel 2. Cita Rasa Kebab di Cafe Kota Cinema Mall, Bekasi (Periode Juli 2019)

\begin{tabular}{|l|l|l|l|}
\hline \multirow{2}{*}{ No. } & Atribut & \multicolumn{2}{|c|}{ Kepuasan } \\
\cline { 2 - 4 } & $\begin{array}{l}\text { Seberapa enak kebab yang } \\
\text { disajikan: }\end{array}$ & 0 & $0 \%$ \\
\hline $\begin{array}{l}\text { a. Rasanya enak, khas, tidak } \\
\text { mudah dilupakan dan membuat } \\
\text { Anda ingin mencoba kembali }\end{array}$ & \begin{tabular}{l} 
Persen \\
\hline $\begin{array}{l}\text { b. Rasanya pas, khas, mudah } \\
\text { diingat, namun belum ada } \\
\text { keinginan untuk mencoba } \\
\text { kembali }\end{array}$
\end{tabular} & 6 & $88 \%$ \\
\hline $\begin{array}{l}\text { c. Rasanya pas, tidak } \\
\text { khas/biasa-biasa saja, tetapi } \\
\text { belum ada keinginan untuk } \\
\text { mencoba kembali }\end{array}$ & 0 & $12 \%$ \\
\hline $\begin{array}{l}\text { d. Rasanya tidak pas dan tidak } \\
\text { khas }\end{array}$ & 0 & $0 \%$ \\
\hline TOTAL & 50 & $100 \%$ \\
\hline
\end{tabular}

Sumber: Data yang diolah Ms. Excel (2019)

Dari 50 orang responden yang diwawancarai, paling banyak menyatakan bahwa cita rasa kebab di Cafe Kota Cinema Mall, Bekasi sebagian besar menyatakan bahwa rasanya pas, khas, tidak mudah dilupakan, dan membuat ingin mencoba kembali sejumlah 44 orang atau 88 persen. Sedangkan 6 orang atau 12 persennya menjawab rasanya pas, khas, mudah diingat tetapi belum ada keinginan untuk mencoba kembali alasannya karena hanya ingin menonton di Kota Cinema Mall, Bekasi dan hanya sekedar mencoba untuk membeli kebab. Secara keseluruhan pelanggan puas dengan cita rasa kebab yang ada di Kota Cinema Mall, Bekasi.

\section{Aroma Kebab di Cafe Kota Cinema Mall, Bekasi}

Berdasarkan observasi penulis di Cafe di Kota Cinema Mall, Bekasi kebab yang diproduksi menghasilkan aroma yang dapat tercium oleh pelanggan. Berikut hasil wawancara terstruktur kepada pelanggan tentang aroma kebab di Cafe di Kota Cinema Mall, Bekasi:

Tabel 3. Aroma Kebab di Cafe Kota Cinema Mall, Bekasi (Periode Juli 2019)

\begin{tabular}{|c|c|c|c|}
\hline \multirow{2}{*}{ No. } & \multirow{2}{*}{ Atribut } & \multicolumn{2}{|c|}{ Kepuasan } \\
\hline & & Jumlah & Persen \\
\hline \multirow[t]{4}{*}{2} & Keharuman kebab: & & \\
\hline & $\begin{array}{l}\text { a. Aroma kebab original } \\
\text { harum, menggugah selera, } \\
\text { dan membuat teringat } \\
\text { dengan aromanya }\end{array}$ & 42 & $84 \%$ \\
\hline & $\begin{array}{l}\text { b. Aroma kebab harum, } \\
\text { kurang menggugah selera, } \\
\text { tetapi tidak teringat dengan } \\
\text { aromanya }\end{array}$ & 6 & $12 \%$ \\
\hline & c. Aroma kebab biasa saja & 0 & $0 \%$ \\
\hline
\end{tabular}




\begin{tabular}{|l|lr|l|l|}
\hline & $\begin{array}{l}\text { d. Aroma kebab tidak } \\
\text { harum dan } \\
\text { menggugah selera }\end{array}$ & tidak & 2 & $4 \%$ \\
\hline
\end{tabular}

Sumber: Data yang diolah Ms. Excel (2019)

Dari 50 orang responden yang diwawancarai, paling banyak menyatakan bahwa aroma kebab original harum, menggugah selera, dan membuat teringat dengan aromanya sebesar 42 orang atau 84 persennya. Sedangkan 6 orang atau 12 persen menyatakan aroma kebab harum, kurang menggugah selera, tetapi tidak teringat dengan aromanya dan 2 orang atau 4 persen menyatakan aroma kebab tidak harum dan tidak menggugah selera. Hal ini disebabkan karena terlalu lama menunggu film sehingga kebab yang jadi kehilangan aroma dan sudah tidak menggugah selera lagi. Namun, secara keseluruhan pelanggan puas dengan aroma Kebab di Cafe Kota Cinema Mall, Bekasi.

\section{Kehigienisan Kebab dan Perlengkapannya di Cafe Kota Cinema Mall, Bekasi}

Berikut hasil wawancara terstruktur tentang kehigienisan dan perlengkapan kebab di Cafe di Kota Cinema Mall, Bekasi:

Tabel 4. Kehigienisan Kebab dan Perlengkapannya di Cafe di Kota Cinema Mall, Bekasi

(Periode Juli 2019)

\begin{tabular}{|c|c|c|c|}
\hline \multirow{2}{*}{ No. } & \multirow{2}{*}{ Atribut } & \multicolumn{2}{|c|}{ Kepuasan } \\
\hline & & Jumlah & Persen \\
\hline \multirow[t]{5}{*}{3} & \multicolumn{3}{|c|}{$\begin{array}{l}\text { Seberapa bersih makanan dan perlengkapan yang } \\
\text { disediakan Cafe Kota Cinema Mall, Bekasi }\end{array}$} \\
\hline & $\begin{array}{l}\text { a. Tidak ada sampah } \\
\text { berserakan pada tempat } \\
\text { memasak kebab dan } \\
\text { bungkusan bersih. }\end{array}$ & 50 & $100 \%$ \\
\hline & $\begin{array}{l}\text { b. Tidak ada sampah } \\
\text { berserakan pada tempat } \\
\text { memasak kebab tapi pada } \\
\text { bungkusannya kurang } \\
\text { bersih. }\end{array}$ & 0 & $0 \%$ \\
\hline & $\begin{array}{l}\text { c. Ada sampah berserakan } \\
\text { pada tempat memasak } \\
\text { kebab dan ada kotoran } \\
\text { pada bungkusannya }\end{array}$ & 0 & $0 \%$ \\
\hline & $\begin{array}{l}\text { d. Ada sampah berserakan } \\
\text { pada tempat memasak } \\
\text { kebab dan peralatannya } \\
\text { kotor }\end{array}$ & 0 & $0 \%$ \\
\hline \multicolumn{2}{|c|}{ TOTAL } & 50 & $100 \%$ \\
\hline
\end{tabular}

Sumber: Data yang diolah Ms. Excel (2019)

Dari 50 orang responden yang diwawancarai semua atau 100 persen menyatakan tidak ada sampah berserakan pada tempat memasak kebab dan bungkusan bersih. Hal ini menunjukan bahwa pelanggan yang merasa puas terhadap kehigienisan kebab dan perlengkapannya di Cafe Kota Cinema
Mall, Bekasi.

\section{B. Tingkat Kepuasan Berdasarkan Harga}

Berdasarkan hasil observasi dan wawancara terstruktur, penulis mendapatkan data pelanggan tentang tingkat kepuasan berdasarkan harga sebagai berikut:

\section{Kesesuaian Harga dengan Kualitas produk di Cafe Kota Cinema Mall, Bekasi}

Berikut hasil wawancara terstruktur tentang harga dan kualitas produk di Cafe di Kota Cinema Mall, Bekasi:

Tabel 5. Kesesuaian Harga dengan Kualitas produk Cafe di Kota Cinema Mall, Bekasi (Periode Juli 2019)

\begin{tabular}{|c|c|c|c|}
\hline \multirow{2}{*}{ No. } & \multirow{2}{*}{ Atribut } & \multicolumn{2}{|c|}{ Kepuasan } \\
\hline & & Jumlah & Persen \\
\hline \multirow[t]{5}{*}{4} & \multicolumn{3}{|c|}{$\begin{array}{l}\text { Harga yang telah ditetapkan sesuai dengan kualitas } \\
\text { produknya: }\end{array}$} \\
\hline & $\begin{array}{l}\text { a. Harga sesuai dengan } \\
\text { kualitas yang diberikan }\end{array}$ & 19 & $38 \%$ \\
\hline & $\begin{array}{llr}\text { b. Harga } & \text { cukup } & \text { berarti } \\
\text { dengan } & \text { kualitas } & \text { yang } \\
\text { diberikan } & & \\
\end{array}$ & 20 & $40 \%$ \\
\hline & $\begin{array}{l}\text { c. Harga tidak sesuai, tetapi } \\
\text { kualitas yang diberikan } \\
\text { memuaskan }\end{array}$ & 7 & $14 \%$ \\
\hline & $\begin{array}{l}\text { d. Harga dan kualitas tidak } \\
\text { memuaskan }\end{array}$ & 4 & $8 \%$ \\
\hline \multicolumn{2}{|c|}{ TOTAL } & 50 & $100 \%$ \\
\hline
\end{tabular}

Sumber: Data yang diolah Ms. Excel (2019)

Dari 50 orang responden yang diwawancarai, sebanyak 20 orang atau 40 persen menyatakan harga sesuai dengan kualitas yang diberikan dan 19 orang atau 38 persen menyatakan harga cukup berarti dengan kualitas yang diberikan. Hal ini dikarenakan karakteristik responden yang mempunyai pekerjaan karyawan dan berpenghasilan Rp 6.000.000,00 (enam juta rupiah) tidak mempersoalkan dengan harga yang yang telah ditetapkan dan sesuai dengan produknya. Sedangkan 7 orang atau 14 persen menyatakan harga tidak sesuai, tetapi kualitas yang diberikan memuaskan dan 4 orang atau 8 persennya menyatakan harga dan kualitas tidak memuaskan dikarenakan karakteristik pelanggan yang masih berstatus mahasiswa atau pelajar belum memiliki penghasilan sehingga harga yang ditetapkan masih terasa terlalu mahal untuk membeli kebab.

\section{Perbandingan Harga Kebab di Cafe Kota} Cinema Mall, Bekasi dengan Kebab lain

Berikut hasil wawancara terstruktur tentang perbandingan harga kebab di Cafe di Kota Cinema Mall, Bekasi. 
Tabel 6. Perbandingan Harga Kebab di Cafe di Kota Cinema Mall, Bekasi dengan Kebab lain (Periode Juli 2019)

\begin{tabular}{|c|c|c|c|}
\hline \multirow{2}{*}{ No. } & \multirow{2}{*}{ Atribut } & \multicolumn{2}{|c|}{ Kepuasan } \\
\hline & & Jumlah & Persen \\
\hline \multirow[t]{5}{*}{5} & \multicolumn{3}{|c|}{$\begin{array}{l}\text { Harga kebab Cafe Kota Cinema Mall, Bekas } \\
\text { dibandingkan dengan kebab harga kebab lain }\end{array}$} \\
\hline & $\begin{array}{l}\text { a. Harga kebab Cafe Kota } \\
\text { Cinema Mall, Bekasi } \\
\text { paling murah }\end{array}$ & 23 & $46 \%$ \\
\hline & $\begin{array}{l}\text { b. Harga kebab Cafe Kota } \\
\text { Cinema Mall, Bekasi lebih } \\
\text { murah, tetapi masih ada } \\
\text { yang lebih murah }\end{array}$ & 4 & $8 \%$ \\
\hline & $\begin{array}{l}\text { c. Harga kebab Cafe Kota } \\
\text { Cinema Mall, Bekasi sama } \\
\text { saja dengan kebab lainnya }\end{array}$ & 2 & $4 \%$ \\
\hline & $\begin{array}{l}\text { d. Harga kebab Cafe Kota } \\
\text { Cinema Mall, Bekasi } \\
\text { paling mahal }\end{array}$ & 21 & $42 \%$ \\
\hline \multicolumn{2}{|c|}{ TOTAL } & 50 & $100 \%$ \\
\hline
\end{tabular}

Sumber: Data yang diolah Ms. Excel (2019)

Dari 50 orang responden yang diwawancarai, 23 orang atau 46 persen menyatakan harga kebab Cafe Kota Cinema Mall, Bekasi paling dan 4 orang atau 8 persen menyatakan harga kebab Cafe Kota Cinema Mall, Bekasi lebih murah, tetapi masih ada yang lebih murah. Hal ini dikarenakan karakteristik responden yang mempunyai pekerjaan karyawan dan berpenghasilan Rp 6.000.000,00 (enam juta rupiah) tidak mempersoalkan dengan harga yang yang telah ditetapkan dan sesuai dengan produknya. Sedangkan 21 orang atau 42 persen menyatakan harga kebab Cafe Kota Cinema Mall, Bekasi paling mahal. Hal ini dikarenakan karena banyaknya pelanggan yang belum bekerja dan masih berstatus mahasiswa atau pelajar sehingga masih merasa terlalu mahal atau mereka hanya sekedar ingin mencoba membeli kebab.

\section{Tingkat Kepuasan Berdasarkan Saluran Distribusi}

Berdasarkan hasil observasi dan wawancara terstruktur, penulis mendapatkan data pelanggan tentang tingkat kepuasan berdasarkan saluran distribusi sebagai berikut:

\section{Lokasi Cafe Kota Cinema Mall, Bekasi}

Berikut hasil wawancara terstruktur tentang lokasi Cafe di Kota Cinema Mall, Bekasi:
Tabel 7. Lokasi Cafe di Kota Cinema Mall, Bekasi (Periode Juli 2019)

\begin{tabular}{|c|c|c|c|}
\hline \multirow{2}{*}{ No. } & \multirow{2}{*}{ Atribut } & \multicolumn{2}{|c|}{ Kepuasan } \\
\hline & & Jumlah & Persen \\
\hline \multirow[t]{5}{*}{6} & \multicolumn{3}{|c|}{ Lokasi Cafe Kota Cinema Mall, Bekasi: } \\
\hline & $\begin{array}{l}\text { a. Sangat mudah } \\
\text { ditemukan lokasinya }\end{array}$ & 50 & $100 \%$ \\
\hline & $\begin{array}{l}\text { b. Mudah ditemukan } \\
\text { lokasinya }\end{array}$ & 0 & $0 \%$ \\
\hline & $\begin{array}{l}\text { c. Kurang mudah } \\
\text { ditemukan lokasinya }\end{array}$ & 0 & $0 \%$ \\
\hline & $\begin{array}{ll}\text { d. Sulit ditemukan } \\
\text { lokasinya }\end{array}$ & 0 & $0 \%$ \\
\hline \multicolumn{2}{|c|}{ TOTAL } & 50 & $100 \%$ \\
\hline
\end{tabular}

Sumber: Data yang diolah Ms. Excel (2019)

Dari 50 orang responden yang diwawancarai, seluruh responden atau 100 persen menyatakan Lokasi Cafe di Kota Cinema Mall, Bekasi sangat mudah ditemukan lokasinya. Hal ini dikarenakan lokasi Kota Cinema Mall, Bekasi yang beralamat di Jl. Parpostel No.85-86, Jatiasih, Bekasi, terletak di pinggir jalan besar dan banyak terdapat perumahan dan sekolahan sehingga mudah dijangkau untuk masyarakat yang ingin mendapatkan hiburan karena tidak perlu lagi ke Jakarta yang jauh dan terkena kemacetan.

\section{Tingkat Kepuasan Berdasarkan Promosi}

Berdasarkan hasil observasi dan wawancara terstruktur, penulis mendapatkan data pelanggan tentang tingkat kepuasan berdasarkan promosi sebagai berikut:

\section{Signage di Cafe Kota Cinema Mall, Bekasi}

Berikut hasil wawancara terstruktur tentang signage di Cafe di Kota Cinema Mall, Bekasi sebagai berikut:

Tabel 8. Signage Cafe di Kota Cinema Mall, Bekasi, Bekasi (Periode Juli 2019)

\begin{tabular}{|c|c|c|c|}
\hline \multirow{2}{*}{ No. } & \multirow{2}{*}{ Atribut } & \multicolumn{2}{|c|}{ Kepuasan } \\
\hline & & Jumlah & Persen \\
\hline \multirow[t]{3}{*}{7} & \multicolumn{3}{|c|}{ Signage Cafe Kota Cinema Mall, Bekasi } \\
\hline & $\begin{array}{l}\text { a. Signage posisi pas (dapat } \\
\text { terlihat dengan baik), } \\
\text { mencolok, dan menggugah } \\
\text { anda untuk membeli } \\
\text { produk di Cafe Kota } \\
\text { Cinema Mall, Bekasi }\end{array}$ & 50 & $100 \%$ \\
\hline & $\begin{array}{l}\text { b. Signage posisi pas (dapat } \\
\text { terlihat dengan baik), } \\
\text { mencolok, namun belum } \\
\text { menggugah anda untuk } \\
\text { membeli produk di Cafe } \\
\text { Kota Cinema Mall, Bekasi }\end{array}$ & 0 & $0 \%$ \\
\hline
\end{tabular}




\begin{tabular}{|l|l|l|l|}
\hline & $\begin{array}{l}\text { c. Signage posisi pas (dapat } \\
\text { terlihat dengan baik), } \\
\text { kurang mencolok, dan } \\
\text { belum menggugah anda } \\
\text { untuk membeli produk di }\end{array}$ & 0 & $0 \%$ \\
$\begin{array}{l}\text { Cafe Kota Cinema Mall, } \\
\text { Bekasi }\end{array}$ & $\begin{array}{l}\text { d. Signage posisinya tidak } \\
\text { pas (kurang dapat terlihat) } \\
\text { dan tidak mencolok }\end{array}$ & 0 & $0 \%$ \\
\hline TOTAL & 50 & $100 \%$ \\
\hline
\end{tabular}

Sumber: Data yang diolah Ms. Excel (2019)

Dari 50 orang responden yang diwawancarai, seluruh responden atau 100 persen menyatakan Signage posisi pas (dapat terlihat dengan baik), mencolok, dan menggugah anda untuk membeli produk di Cafe Kota Cinema Mall, Bekasi. Hal ini menunjukan bahwa tingkat kepuasan berdasarkan promosi di Cafe Kota Cinema Mall, Bekasi yaitu puas karena dengan signage posisinya pas (dapat terlihat dengan baik), mencolok, dan menggugah pelanggan untuk membeli produk di Cafe Kota Cinema Mall, Bekasi.

\section{E. Tingkat Kepuasan Berdasarkan Bukti Fisik}

Berdasarkan hasil observasi dan wawancara terstruktur, penulis mendapatkan data pelanggan tentang tingkat kepuasan kerdasarkan bukti fisik sebagai berikut:

\section{Furniture di Cafe Kota Cinema Mall, Bekasi}

Hasil wawancara terstruktur tentang furniture di Cafe di Kota Cinema Mall, Bekasi:

Tabel.9.Furniture di Cafe di Kota Cinema Mall, Bekasi (Periode Juli 2019)

\begin{tabular}{|c|c|c|c|}
\hline \multirow{2}{*}{ No. } & \multirow{2}{*}{ Atribut } & \multicolumn{2}{|c|}{ Kepuasan } \\
\hline & & Jumlah & Persen \\
\hline \multirow[t]{5}{*}{8} & $\begin{array}{l}\text { Furniture Cafe Kota } \\
\text { Cinema Mall, Bekasi: }\end{array}$ & & \\
\hline & $\begin{array}{l}\text { a. Furniture Cafe terjamin } \\
\text { kebersihannya } \\
\text { penataan tata letak tepat } \\
\text { dan menarik }\end{array}$ & 50 & $100 \%$ \\
\hline & $\begin{array}{l}\text { b. Furniture Cafe terjamin } \\
\text { kebersihannya, tetapi } \\
\text { penataan tata letak kurang } \\
\text { tepat dan kurang menarik }\end{array}$ & 0 & $0 \%$ \\
\hline & $\begin{array}{l}\text { c. Furniture Cafe cukup } \\
\text { terjamin kebersihannya } \\
\text { serta penataan tata letak } \\
\text { tepat dan menarik }\end{array}$ & 0 & $0 \%$ \\
\hline & $\begin{array}{l}\text { d. Furniture Cafe tidak } \\
\text { terjamin kebersihannya dan } \\
\text { penataan tata letak tidak } \\
\text { tepat dan tidak menarik }\end{array}$ & 0 & $0 \%$ \\
\hline \multicolumn{2}{|c|}{ TOTAL } & 50 & $100 \%$ \\
\hline
\end{tabular}

Dari 50 orang responden yang diwawancarai, seluruh responden atau 100 persen menyatakan Furniture Cafe terjamin kebersihannya serta penataan tata letak tepat dan menarik. Hal ini menunjukan bahwa tingkat kepuasan berdasarkan bukti fisik di Cafe di Kota Cinema Mall, Bekasi. yaitu puas karena furniture Cafe terjamin kebersihannya serta penataan tata letak tepat dan menarik.

\section{F. Tingkat Kepuasan Berdasarkan Proses}

Kecepatan transaksi di Cafe Kota Cinema Mall, Bekasi. Berdasarkan hasil observasi dan wawancara terstruktur, penulis mendapatkan data pelanggan tentang tingkat kepuasan berdasarkan proses sebagai berikut:

\section{Kecepatan Kasir dalam Memenuhi Pesanan di Cafe Kota Cinema Mall, Bekasi}

Berikut merupakan hasil wawancara terstruktur di Cafe di Kota Cinema Mall, Bekasi:

Tabel.10. Kecepatan Kasir dalam Memenuhi Pesanan di Cafe di Kota Cinema Mall, Bekasi

\begin{tabular}{|c|c|c|c|}
\hline \multirow{2}{*}{ No. } & \multirow{2}{*}{ Atribut } & \multicolumn{2}{|c|}{ Kepuasan } \\
\hline & & Jumlah & Persen \\
\hline \multirow[t]{5}{*}{9} & \multicolumn{3}{|c|}{ Seberapa cepat kasir dapat memenuhi pesanan: } \\
\hline & $\begin{array}{l}\text { a. Waktu transaksi kurang } \\
\text { dari } 5 \text { menit }\end{array}$ & 45 & $90 \%$ \\
\hline & $\begin{array}{l}\text { b. Waktu transaksi 5-7 } \\
\text { menit }\end{array}$ & 3 & $6 \%$ \\
\hline & $\begin{array}{lll}\begin{array}{l}\text { c.Waktu transaksi } \\
\text { menit }\end{array} & 8-10 \\
\end{array}$ & 2 & $4 \%$ \\
\hline & $\begin{array}{l}\text { d. Waktu transaksi 11-13 } \\
\text { menit }\end{array}$ & 0 & $0 \%$ \\
\hline \multicolumn{2}{|c|}{ TOTAL } & 50 & $100 \%$ \\
\hline
\end{tabular}

Sumber: Data yang diolah Ms. Excel (2019)

Dari 50 orang responden yang diwawancarai, 45 orang atau 90 persen tentang seberapa cepat kasir dapat memenuhi pesanan menyatakan waktu transaksi kurang dari 5 menit atau sesuai dengan SOP yang telah ditetapkan perusahaan, sedangkan 3 orang atau 6 persen menyatakan waktu transaksi 5-7 menit dan sisanya hanya 2 orang atau 4 persennya saja yang menyatakan waktu transaksi 8-10 menit. Hal ini menunjukan secara keseluruhan pelanggan merasa puas terhadap bahwa tingkat kepuasan berdasarkan proses kecepatan kasir dalam memenuhi pesanan di Cafe di Kota Cinema Mall, Bekasi sedangkan alasan untuk pelanggan yang tidak puas dikarenakan kurangnya petugas dan suasana Café terlalu ramai sehingga banyaknya orderan yang membuat waktu transaksi lama. Ketika kasir menerima pesanan yang terlalu banyak bagian kitchen atau bar kekurangan orang untuk menyajikan makanan sehingga dibutuhkan waktu yang agak lama. Hal ini menyebabkan pelanggan terlalu lama menunggu di pick up order.

\section{G. Tingkat Kepuasan Berdasarkan Orang}

Penjelasan kasir terhadap penawaran kebab. Berdasarkan hasil observasi dan wawancara 
terstruktur, penulis mendapatkan data pelanggan tentang tingkat kepuasan berdasarkan orang sebagai berikut:

\section{Penjelasan Kasir di Cafe Kota Cinema Mall,} Bekasi

Berikut merupakan hasil wawancara terstruktur teantang kepuasan berdasarkan orang di Cafe di Kota Cinema Mall, Bekasi:

Tabel 11. Penjelasan Kasir di Cafe di Kota Cinema Mall, Bekasi (Periode Juli 2019)

\begin{tabular}{|c|c|c|c|}
\hline \multirow{2}{*}{ No. } & \multirow{2}{*}{ Atribut } & \multicolumn{2}{|c|}{ Kepuasan } \\
\hline & & Jumlah & Persen \\
\hline \multirow[t]{5}{*}{10} & \multicolumn{3}{|c|}{$\begin{array}{l}\text { Kasir memberikan informasi yang dibutuhkan } \\
\text { pelanggan: }\end{array}$} \\
\hline & $\begin{array}{l}\text { a. Kasir mengerti yang } \\
\text { saya tanyakan, } \\
\text { memberikan jawaban } \\
\text { yang dapat dimengerti } \\
\text { oleh saya, dan tempo } \\
\text { bicaranya cepat dan tepat }\end{array}$ & 49 & $98 \%$ \\
\hline & $\begin{array}{l}\text { b. Kasir mengerti yang } \\
\text { saya tanyakan, } \\
\text { memberikan jawaban } \\
\text { yang dapat dmengerti } \\
\text { oleh saya, tetapi tempo } \\
\text { bicaranya kurang tepat } \\
\text { (terlalu cepat atau } \\
\text { lambat) }\end{array}$ & 0 & $0 \%$ \\
\hline & $\begin{array}{l}\text { c. Kasir mengerti yang } \\
\text { saya tanyakan, tetapi } \\
\text { memberikan jawaban } \\
\text { yang tidak dimengerti } \\
\text { oleh saya, tempo } \\
\text { bicaranya kurang tepat } \\
\text { (terlalu cepat) }\end{array}$ & 1 & $2 \%$ \\
\hline & $\begin{array}{l}\text { d. Kasir tidak mengerti } \\
\text { yang saya tanyakan dan } \\
\text { jawaban kasir atas } \\
\text { pertanyaan pelanggan } \\
\text { kurang jelas }\end{array}$ & 0 & $0 \%$ \\
\hline \multicolumn{2}{|c|}{ TOTAL } & 50 & $100 \%$ \\
\hline
\end{tabular}

Sumber: Data yang diolah Ms. Excel (2019)

Dari 50 orang responden yang diwawancarai, hampir seluruhnya atau 49 orang (98 persen) tentang penjelasan kasir di Cafe di Kota Cinema Mall, Bekasi menyatakan kasir mengerti yang saya tanyakan, memberikan jawaban yang dapat dimengerti oleh saya, dan tempo bicaranya cepat dan tepat dan hanya 1 orang ( 2 persen) saja yang menyatakan kasir mengerti yang saya tanyakan, tetapi memberikan jawaban yang tidak dimengerti oleh saya, tempo bicaranya kurang tepat (terlalu cepat). Hal ini menunjukan secara keseluruhan bahwa tingkat kepuasan berdasarkan penawaran kebab di Cafe di Kota Cinema Mall, Bekasi merasa puas terhadap penjelasan kasir dalam penawaran kebab, sedangkan alasan untuk pelanggan yang merasa tempo bicara kasir kurang tepat dalam penyampaian kepada pelanggan di karenakan suasana kasir ramai dan untuk menghindari antrian yang panjang sehingga dalam penyampaian kasir terlalu cepat.

\section{KESIMPULAN}

Setelah melakukan penelitian di Cafe di Kota Cinema Mall, Bekasi dan mendapat hasil penelitian mengenai kepuasan pelanggan, maka penulis menyimpulkan bahwa:

1. Karakteristik pelanggan pada Cafe di Kota Cinema Mall, Bekasi didominasi oleh pelanggan yang berdasarkan jenis kelamin yaitu laki-laki, berdasarkan umur didominasi oleh umur 21 tahun sampai dengan 25 tahun, berdasarkan pekerjaan didominasi oleh mahasiswa atau pelajar dan karyawan swasta, dan berdasarkan penghasilan didominasi oleh pelanggan yang belum memiliki penghasilan.

2. Analisis kepuasan pelanggan berdasarkan bauran pemasaran yang diteliti penulis berdasarkan produk, harga, saluran distribusi, promosi, bukti fisik, proses dan orang yaitu pelanggan menyatakan sangat puas terhadap kebab yang disajikan di Cafe di Kota Cinema Mall, Bekasi.

3. Kendala yang dihadapi oleh crew adalah tentang antrian panjang pada saat transaksi karena waktu penyajian makanan yang terlalu lama dikarenakan kekurangan crew penyaji saat jumlah pengunjung banyak. Hal ini dapat diatasi dengan sebaiknya untuk petugas harus lengkap sesuai job desk masing-masing seperti pick up order, bar, kichen, kasir dan server agar waktu transaksi kurang dari 5 menit

Tabel 12. Analisis Keseluruhan Kepuasan Pelanggan di Cafe di Kota Cinema Mall, Bekasi (Periode Juli 2019)

\begin{tabular}{|c|c|c|c|c|c|c|c|c|c|}
\hline \multirow[t]{2}{*}{ No } & \multirow[t]{2}{*}{$\begin{array}{l}\text { Bauran } \\
\text { Pemasaran }\end{array}$} & \multicolumn{2}{|c|}{ Sangat Puas } & \multicolumn{2}{|c|}{ Puas } & \multicolumn{2}{|c|}{ Tidak Puas } & \multicolumn{2}{|c|}{$\begin{array}{c}\text { Sangat Tidak } \\
\text { Puas }\end{array}$} \\
\hline & & Jml & $\%$ & Jml & $\%$ & Jml & $\%$ & Jml & $\%$ \\
\hline A & Tingkat Kep & $\operatorname{asan} I$ & rdasark & n Proc & & & & & \\
\hline 1 & Cita Rasa & 44 & $88 \%$ & 6 & $12 \%$ & & & & \\
\hline 2 & Aroma & 42 & $84 \%$ & 6 & $12 \%$ & & & 2 & $4 \%$ \\
\hline 3 & Kehigienisa & 50 & $100 \%$ & & & & & & \\
\hline
\end{tabular}




\begin{tabular}{|c|c|c|c|c|c|c|c|c|c|}
\hline & $\mathrm{n}$ & & & & & & & & \\
\hline B & \multicolumn{9}{|c|}{ Tingkat Kepuasan Berdasarkan Harga } \\
\hline 4 & $\begin{array}{l}\text { Kesesuaian } \\
\text { Harga } \\
\text { dengan } \\
\text { Kualitas } \\
\text { produk }\end{array}$ & 19 & 38 & 20 & $40 \%$ & 7 & $14 \%$ & 4 & $8 \%$ \\
\hline 5 & $\begin{array}{l}\text { Perbandinga } \\
\text { n Harga }\end{array}$ & 23 & $46 \%$ & 4 & $8 \%$ & 2 & $4 \%$ & 21 & $42 \%$ \\
\hline $\mathbf{C}$ & \multicolumn{9}{|c|}{ Tingkat Kepuasan Berdasarkan Saluran Distribusi } \\
\hline 6 & Lokasi & 50 & $100 \%$ & & & & & & \\
\hline $\mathbf{D}$ & \multicolumn{9}{|c|}{ Tingkat Kepuasan Berdasarkan Promosi } \\
\hline 7 & Signage & 50 & $100 \%$ & & & & & & \\
\hline $\mathbf{E}$ & \multicolumn{9}{|l|}{ Bukti Fisik } \\
\hline 8 & Furniture & 50 & $100 \%$ & & & & & & \\
\hline $\mathbf{F}$ & \multicolumn{9}{|c|}{ Tingkat Kepuasan Berdasarkan Proses } \\
\hline 9 & $\begin{array}{l}\text { Kecepatan } \\
\text { Kasir }\end{array}$ & 45 & $90 \%$ & 3 & $6 \%$ & 2 & $4 \%$ & & \\
\hline $\mathbf{G}$ & \multicolumn{9}{|c|}{ Tingkat Kepuasan Berdasarkan Orang } \\
\hline 10 & $\begin{array}{l}\text { Penjelasan } \\
\text { Kasir }\end{array}$ & 49 & $98 \%$ & & & 1 & $2 \%$ & & \\
\hline & TOTAL & 422 & $84,4 \%$ & 39 & $7,8 \%$ & 12 & $2,4 \%$ & 27 & $5,4 \%$ \\
\hline
\end{tabular}

Sumber: Data yang diolah Ms. Excel (2019)

Analisis tingkat kepuasan konsumen Cafe di Kota Cinema Mall, Bekasi sebagian besar sebanyak 84 persen berada pada tingkat "sangat puas", sedangkan yang berada pada tingkat "puas" terhadap Cafe di Kota Cinema Mall, Bekasi 7,8 persen, sisanya 5,4 persen pada tingkat "sangat tidak puas" dan 2,4 persen berada pada tingkat "tidak puas". Dengan demikian, dapat dianalisis bahwa tingkat kepuasan konsumen Cafe di Kota Cinema Mall, Bekasi secara keseluruhan berada pada tingkat "sangat puas".

\section{REFERENSI}

Atmaja, J. (2018). Ecodemica. Jurnal Ecodemica: Jurnal Ekonomi, Manajemen, dan Bisnis (Vol. 2).

Chairawani, T. R. S., Iskandarin, \& Emalisa. (2018). ANALISIS KEPUASAN KONSUMEN TERHADAP KEDAI KOPI ULEE KARENG DI KOTA MEDAN. Journal on Social Economy of Agriculture and Agribusines, 9(10), 1-18.

Fachriza, F. I., \& Moeliono, N. (2017). Pengaruh Bauran Pemasaran Terhadap Keputusan Pembelian Rokok Mild. Jurnal Ecodemica: Jurnal Ekonomi, Manajemen, Dan Bisnis, 1(2), 139-148. https://doi.org/10.31311
/JECO.V1I2.1332

Kotler, P., \& Gary Armstrong. (2009). Marketing: An Introduction (Ninth Edit). USA: Pearson Prentice Hall.

Mardalis. (2004). Metode Penelitian Suatu Pendekatan Proposal. Jakarta: Bumi Aksara.

Ningratri, Y. A. (2017). Analisis Pengaruh Strategi Bauran Pemasaran Jasa (3P)Terhadap Keputusan Mahasiswa Memilih STIM SUKMA Medan. Remik, 3. https://doi.org/10.31227/OSF.IO/SWG4A

Pradiatiningtyas, D. (2015). Analisis Perbedaan Penerapan Marketing Mix Dalam Meningkatkan Penjualan (Kajian Terhadap Bisnis Perhotelan Bintang dan Non Bintang Di Yogyakarta). Jurnal Khasanah Ilmu, 1.

Sazly, S. (2018). Pengaruh Service Quality Terhadap Customer Satisfaction dan Customer Loyalty (Studi Kasus Pada LP3I Karang Tengah, Tangerang). Widya Cipta - Jurnal Sekretari Dan Manajemen, 2(2), 285-293. 